Contents List available at RAZI Publishing

Acta Informatica Malaysia(AIM)

Journal Homepage: http://www.razipublishing.com/journals/acta-informatica-malaysia

https://doi.org/10.26480/aim.01.2017.17.21

\title{
UTHM STUDENT PLANNER
}

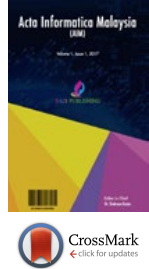

Chin Pei Yuan, Norfaradilla Wahid, Shahreen Kasim, Mohd Farhan Md Fudzee, Azizul Azhar Ramli, Hairulnizam Mahdin, Seah Choon Sen

Faculty Computer Science and Information Technology, University Tun Hussein Onn Malaysia, Johor, Malaysia aelisyuan@gmail.com, faradila@uthm.edu.my, \{hana, shahreen, farhan, azizulr, hairuln\}@ uthm.edu.my, seanseah0702@gmail.com

This is an open access article distributed under the Creative Commons Attribution License, which permits unrestricted use, distribution, and reproduction in any medium, provided the original work is properly cited.

\section{ARTICLE DETAILS}

Article history:

Received 22 January 2017 Accepted 03 February 2017 Available online 05 February 2017

\begin{abstract}
UTHM Student Planner is an application which includes web version and mobile version. It is a system that is use to help student to manage the time. The purpose of developing this application is to solve the time management problem and increase the awareness on the importance of time management. Object Oriented Software Development (OOSD) Model is being use as a guideline and standard along the process of system development. Overall, this system includes calendar, reminder, notes and a function to find people. It is capable to improve student's time management which will leads to the betterment of student performance in academics.
\end{abstract}

\section{Introduction}

In this era of technology, the need of having an excellent daily or monthly planner is highly recommended for people who wish to have a well arrange day. Nowadays, many university students lack skills in the time management and forget about the importance of time management. Students can slip right up on the deadline for assignment or project easily and without noticing by the user.

Based on these issues, we propose to develop a planner to help UTHM students to solve the time management problem and increase the awareness on the importance of time management. The UTHM Student Planner is a multifunction application that will be used to manage the time information by the UTHM students.

The main problem addressed by the project is how to improve time management of student. For students do not own a medium to refer the important dates and events together it can cause a problem when there is an overlapping or a clash for the event at the same time. The objectives of the project are as follows:

1. To develop a mobile-based UTHM Students Planner

2. To design a multifunction planner to ease the students in UTHM.

3. To provide students with a planner application that can save timetable, notes and reminders for the students to manage their time.

The rest of the paper is organized as follows: Section II describes the literature review of this project. Section III presents the methodology to develop this application. Section IV is the performance analysis. Section V is the conclusion. Finally, Section VI references related to this project.

\section{Literature Review}

The modern concept of time management is the act of planning the amount of the time people spends on which activities [1]. In business, time management refers to the development of processes and tools that increase efficiency and productivity [2]. In the academics, time management will let the students understand how to manage their time in school while having tasks, projects, social life and stop procrastinating. By managing time precisely, students can spend more time for hobbies, spare-time activities and empower their study since them able to spend more time on important subjects. Therefore, time management can prevent poor performance, stress, pressure, and the waste of time [3].

As mentioned earlier, the goal of this project is to design and develop an easy to use a multifunction planner application for the students in University Tun Hussein Onn Malaysia (UTHM). Mostly the student will use a planner application on the smartphone rather than write it on the paper. Some of the students in UTHM are using a personal organizer or a piece of paper to mark down all the important dates and notes. However, a personal organizer or a piece of paper will not remind the users about the important date. There are also students using a calendar application available in the smartphones, but the calendar application can only mark down all the important dates. The calendar application in the smartphone is not built with the notes function to allow the students to save some important notes. This section will discuss on the existing application that is related to the project.

\section{A. Study of Existing Planner System and Application}

A mobile-based application is similar to any other application but it consists of web-based HTML pages that are linked together and accessed over the Internet. While for mobile, it is typically Wi-Fi or 3G or 4G networks. The obvious characteristic that distinguishes a mobile website from a standard website is the fact that it is designed for the smaller handheld display and touch-screen interface [4]. For a mobile-based application, the mobile website is instantly accessible to users via the browser when the users are using laptop or desktop or access using the app when the users access via smartphone. A single mobile-based application can reach users across many different types of mobile devices. For example, the smartphones, tablet, laptop etc., therefore it is much more dynamic than an application in terms of pure flexibility to update content. Finally, a mobile-based application can be developed as database-driven web applications that act very much like native apps. The following list outlines the existing application available in the market.

\section{1) Life Reminder}

Life Reminder [5] is a free and simple but powerful reminder in the mobile market. Figure 1 shows the sample of Life Reminder user interface. It allows the user to create a reminder for user's daily tasks easily. Life Reminder mainly supports for four kinds of reminders under date or time-based which is the call reminder, task reminder, message reminder and the email reminder.

However, Life Reminder only has one function in general which is to remind user with notification. User cannot directly add or plan their own event or manage their time in this application which is inconvenient to the user to manage the time.

In Figure 1, the four square button represent the call reminder, task reminder, message reminder and the email reminder. User can enter the reminder test, classify the reminder, notify dates and save the reminder.

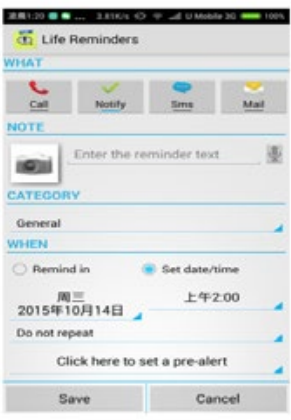

Figure 1. Sample of Life Reminder User Interface 


\section{2) A Calendar}

A Calendar [6] is a free user-friendly calendar which is developed as a replacement for the Google calendar application. An example of the user interface of A Calendar is shown in Figure 2. The a Calendar provides three type of calendar interface which is in monthly view, weekly view or daily view. The calendar view provides can be swiped between to ease the user according to user needs.

This calendar allows the user to add in events information i.e. the date, time, venue, description etc. The events can be added by tapping the add symbol on the top of the toolbars. A Calendar also can be a reminder to remind user about the upcoming events in alarm, pop-up notifications, SMS message or in an email. It also includes a home screen widget which can display the calendar and provide an easy display for the user to view all the events. All the new events are easy to be created and added to the user calendar. All the events will be synchronized to the Google calendar as well. In Figure 2, it shows the user interface of a Calendar in weekly view and a monthly view at the right-bottom corner.

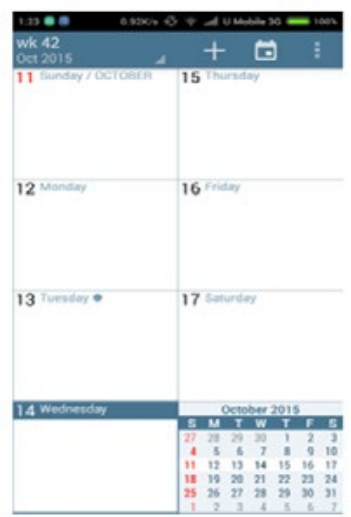

Figure 2. Sample of a Calendar User Interface

\section{3). Student Agenda}

Student Agenda [7] is a free planner designed specifically for the students to arrange themselves. Figure 3 shows the user interface of the Student Agenda. It includes four main functions for the users which are subjects, timetable, events and marks. It also includes monthly calendar for students to add and view the information about the events, homework, appointments, test, meeting, classes etc. The weekly calendar also provided to show the details insert in week form while the daily calendar will show the events on the particular date.

However, the user must insert all the subjects in order to arrange for the timetable. The subjects that are not saved in subjects function will not be able to be inserted into the timetable. The marks function is to allow users to insert the details of the marks of a particular subject.

In Figure 3, four functions represent subjects, timetable, events and marks respectively in the menu page. There are daily, weekly and monthly calendar available on the navigation bar.

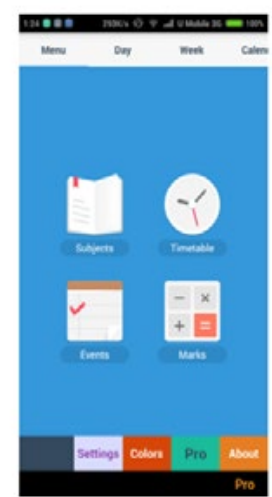

Figure 3. Sample of Student Agenda User Interface

\section{Methodology}

In this chapter, the methodology used for develop the proposed project will be discussed in detail. UTHM Student Planner is an application developed for the students in University Tun Hussein Onn Malaysia (UTHM).The methodology that has been chosen to develop this application was Object Oriented Software Development. Object Oriented Software Development would analyze problem first instead of building a prototype in the requirement of specification phase [8].

\section{A. System Analysis}

In system analysis, it will analyze the process in terms of data flow and help to identify the input and output of the UTHM Student Planner. The analysis would include the three applications which had been compared in II, Life Reminder, ACalendar and Student Agenda. These applications were being analyzed and compared to each other. The functions and data collected would be analyzed carefully about what does the existing application lack of and in order to develop a student planner with more functionality based on mobile-based application platform. Therefore, weaknesses and strengths in the existing application can be identified and improvements can be made to develop the UTHM Student Planner This process was important in helping designer to gain some user experience for a better understanding in user needs. The information gathered through testing the applications was interpreted and compared.

In this project, Unified Modeling Language (UML) is used to present the use case diagram to illustrate each function in the system. It can be used with all processes, throughout the software development life cycle, and across different implementation technologies. Use case diagram shows that the activities and functions that actor can do in the application. Figure 4 illustrates the overall use case of the UTHM Student Planner.

The activity diagram briefly displays the summary workflows of the system. The activity diagram is used to shows the core functions of the proposed application. It shows the activities that can be performed by the user and also the flow of the activities. Figure 5 shows the Activity Diagram of the UTHM Student Planner.

\section{B. System Design}

At the beginning of system design, the user interface of the proposed application was drafted and created. The interface design for the UTHM Student Planner will be able to fulfill the user's requirements which are also need to be user-friendly. The development of the proposed application is based on use case diagram, sequence diagram and activity diagram. The free online drawing software "Draw.io" was used to design the use case diagram, sequence diagram and user activity diagram.

Android Studio was used to convert the proposed application in web version to mobile version. Android Studio is chosen for developing the proposed application because it is free, and available under the Apache License. Besides, the programming language used to develop the proposed application is HTML, PHP and CSS.

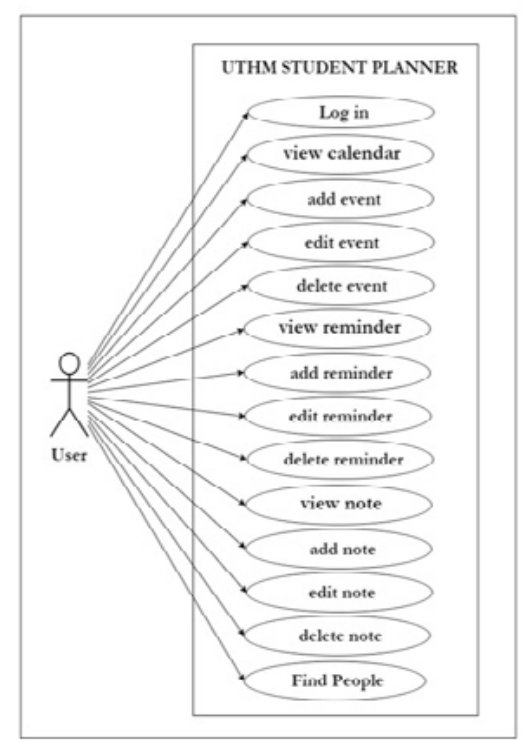

Figure 4. Use Case Diagram of the UTIIM Student Planne 


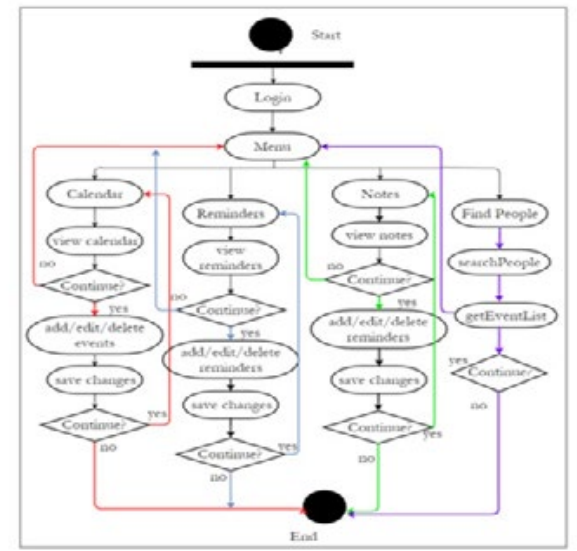

Figure 5. Activity Diagram for UTHM Student Planner

User interface design is important to allow users interaction with the application. The user interface design aim to create a user-friendly environment. It is an important process which gives conception about input that will be inserted and output will be displayed. Figure 6, Figure 7, and Figure 8 demonstrate the page interface for the system.

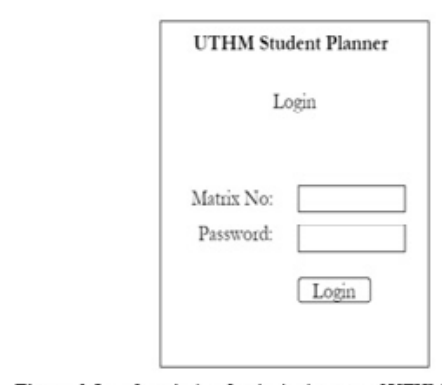

Figure 6. Interface design for the login page of UTHM Student Planner

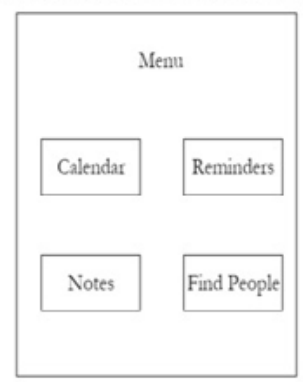

Figure 7. Interface design for user to choose function from menu
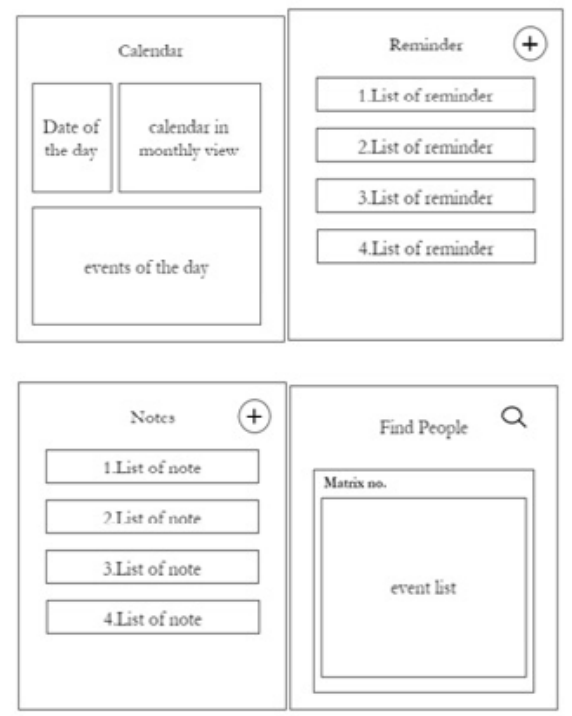

Figure 8. Interface design for the main function

\section{Performance Analysis}

In implementation phase, it is about implementing the system design and developing it into the real system. Coding of UTHM Student Planner is involved. Several modules of the UTHM Student Planner will be designed in the design phase and transform it into a program to be executed.

\section{A. Login Page}

The main interface of the application is crucial for the interaction between users and the application. Figure 9 shows the login page of UTHM Student Planner. The users need to fill in the matric number and password in order to login to the system.

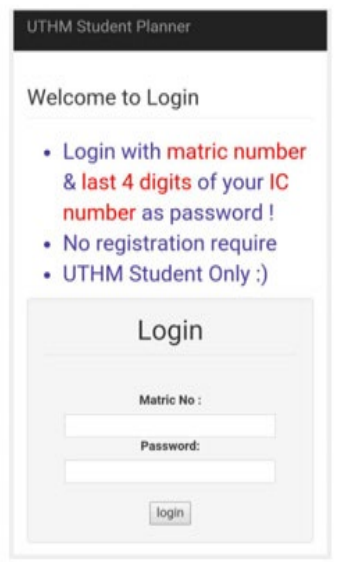

Figure 9. Login Page of UTHM Student Planner

\section{B. Menu Page}

There are four button shows in the menu page which is the calendar button, reminder button, notes button and also the find people button. When users touch the button, the application start the activity name which responding to the button. Figure 10 shows Interface of menu page.

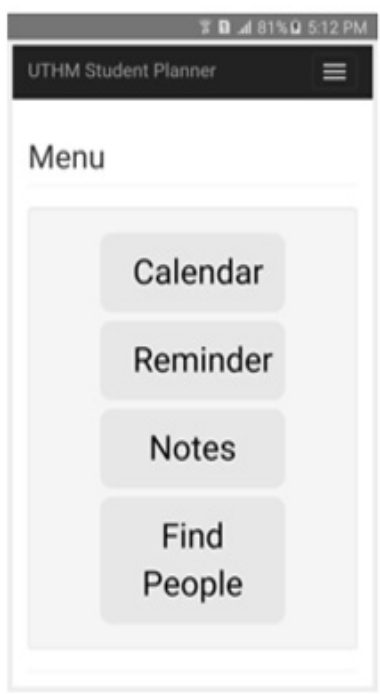

Figure 10. Interface of menu page

\section{Main Function Page}

The Figure 11 shows the interface of the calendar, reminder, notes and find people. 


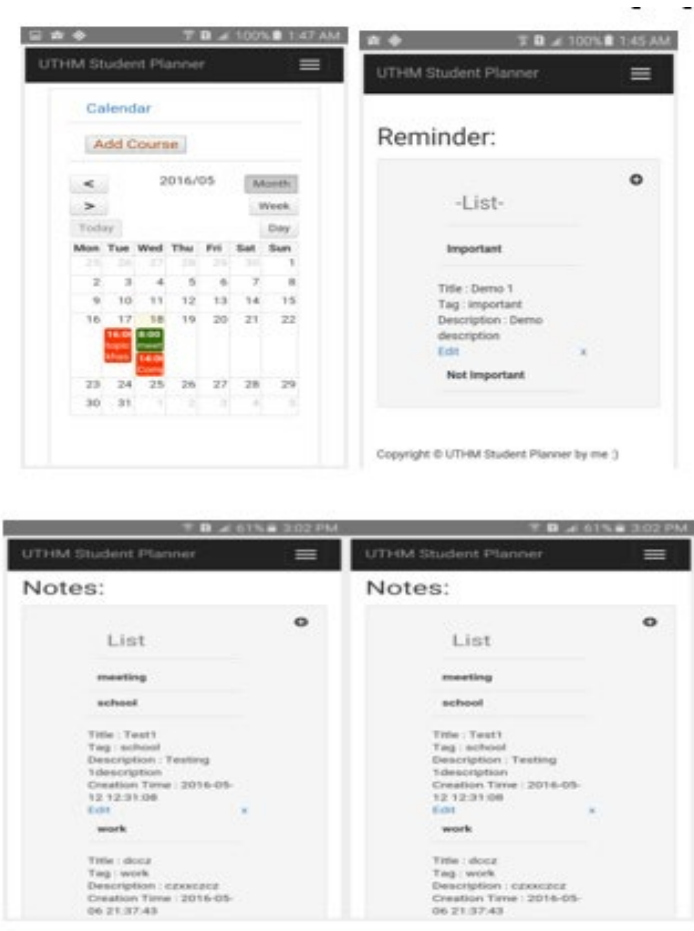

Figure 11. Interface of the main function

The calendar function provides daily calendar, weekly calendar and monthly calendar that allow students to add the course or event. User can add, edit and delete the course or event. The reminder function allow user to add edit and delete the task reminder. Reminder added provides a notification to remind user. User can add, edit and delete the notes. The notes added can be classified according to user needs. For the find people, user can search for the other student's event list by using the matric number.

\section{Testing}

Functional testing is used to ensure the function of the proposed system work properly. Functional testing has been done on the proposed application. All of the function in the application will be tested to make sure there is no errors occur. Table 1 shows the testing on each module of UTHM Student Planner and its result. Figure 12 shows the overall interface evaluation graph and Figure 13 shows the overall user friendly evaluation graph. Overall, 4 students from FSKTM agree that UTHM Student Planner is easy to use and there are 6 students agree that this application is moderate for user friendly acceptance.

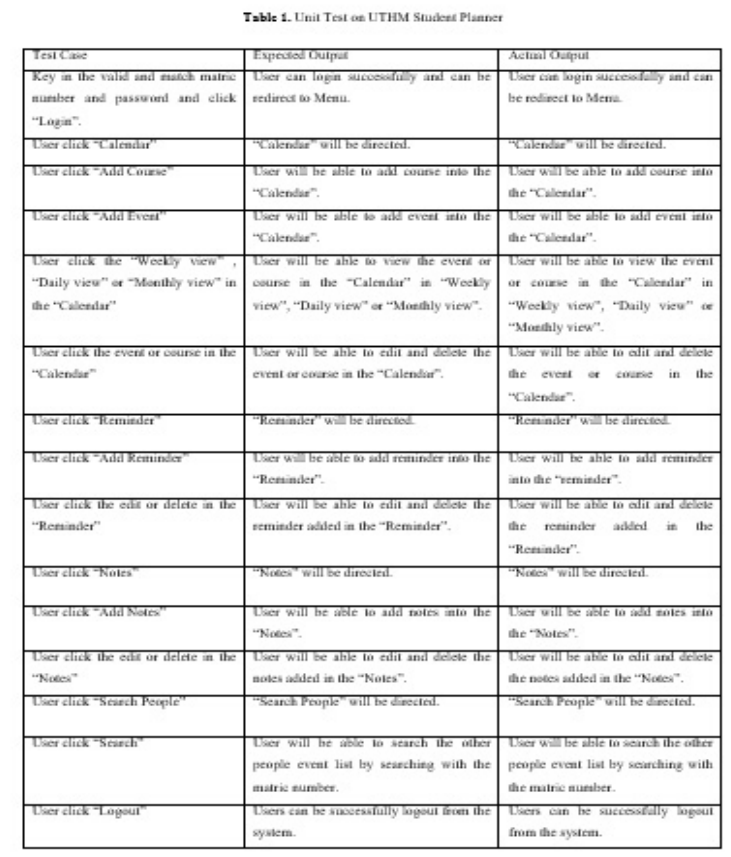

Overall Interface Evaluation

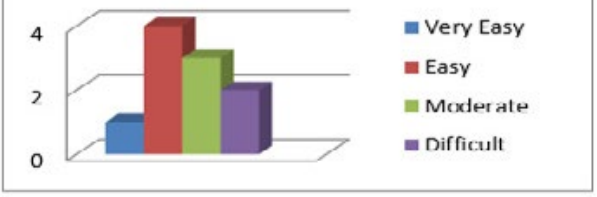

Figure 12. Overall Interface Evaluation Graph

\section{Overall User Friendly Evaluation}

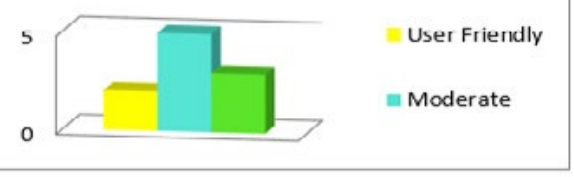

Figure 13. Overall User Friendly Evaluation Graph

\section{Conclusion}

UTHM Student Planner is an application developed in web version and also mobile version. This application can help user to have better time management and help students to submit their works before the due date. In the conclusion the advantages of the application, constraints faced during the development of the application and proposed improvements to the application in the future will be discussed in detail.

The advantages of this application have been identified. The application provides a better time management to user. User can easily save any important note or dates easily. In addition, the application can use to find other student to view their event list.

Although the objectives of this project have been achieved, there are limitations in the actual system. Firstly, the events added by user are including the private event. However, this application will display out all event added by user. So to overcome this problem, the event added by user should be able to choose either is public or private event and only the public event will be display out in the People Search.

During the application developments process, there are lots of problems had faced. First of all, the problems had faced is lack of experience. Initially, it is planned to develop a native application for better users' experience. However, it requires many resource and knowledge are needed to complete this project. At the beginning of this project, the application is developing in native ways. However, due to lack of knowledge in Java programming, this project is stuck and no progress in a long period of time. Therefore, after the mid-semester break, with the discussion with my supervisor, this application is redone by using web version and tries to convert the web version in mobile version.

In the future, UTHM Student Planner can be improved or upgrade into a better application with more complete function. Therefore, users would use it to improve the time management skills.

In conclusion, UTHM Student Planner has achieved its objectives outlined at the beginning of its development planning. Even though the system had achieving all objective, this system still requires more improvement so that it could really help the student in time management.

\section{References}

1. E. Ho and C. Woods, "What is Time Management? - Definition, Examples \& Studies - Video \& Lesson Transcript | Study.com",Study.com, 2016. [Online]. Available: http://study.com/academy/lesson/what-is-time-managementdefinition-examples-studies.html. [Accessed: 11- Oct- 2015].

2. S. Ward, “Time Management: What It Is, Why It Is and How to Use It",About. com Money, 2016. [Online]. Available: http://sbinfocanada.about.com/od/ timemanagement/g/timemanagement.htm. [Accessed: 11- Oct- 2015]. 3. E. Kee, "College Skills: Time Management | \#TheGuide",Openlab.citytech. cuny.edu, 2016. [Online]. Available: https://openlab.citytech.cuny.edu/ theguide/2013/10/30/college-skills-time-management-3/. 

Informatica Malaysia 1(1) (2017) 17-21

[Accessed: 12- Dec- 2015].

4. J . Summerfield, "Mobile Website vs. Mobile App (Application) - Which is Best for Your Organization? | Human Service Solutions", Hswsolutions. com, 2016. [Online]. Available: https://www.hswsolutions.com/services/ mobile-web-development/mobile-website-vs-apps/. [Accessed: 27- Apr2016].

5. "F.A.Q. - Life Reminders", Lifereminders.eu, 2016. [Online]. Available: http://www.lifereminders.eu/index.php?id=faq. [Accessed: 18- Nov- 2015].

6. P. Daniel, "aCalendar Android Review”, Download3k.com, 2016. [Online].
Available: http://www.download3k.com/articles/aCalendar-AndroidReview-01209. [Accessed: 18- Nov- 2015].

7. C. de Carvalho, "Student Agenda", Play.google.com, 2016. [Online]. Available: https://play.google.com/store/apps/details?id=com.clawdyvan. agendadigitalaluno\&hl=en. [Accessed: 18- Nov- 2015].

8. M. Piefel, "Object Oriented Software Development", Object Oriented Software Development The new way of thinking, vol. 1, pp. 9-13, 1996. 